\title{
Management of Malignant Chest Wall Tumors
}

\author{
Farhan Ahmad Majeed ${ }^{1}$, Ahmad Ali $^{2}$, Sohail Saqib Chatha ${ }^{3}$, Ghazanfar Ahmad ${ }^{4}$, Adeel Wyne ${ }^{2}$ and Nadeem \\ Paracha ${ }^{5}$ \\ ${ }^{1}$ Department of Thoracic Surgery, Combined Military Hospital, Multan, Pakistan \\ ${ }^{2}$ Department of Thoracic Surgery, Combined Military Hospital, Multan, Pakistan \\ ${ }^{3}$ Department of Thoracic Surgery, Combined Military Hospital, Rawalpindi, Pakistan \\ ${ }^{4}$ Department of Plastic Surgery, Combined Military Hospital, Multan, Pakistan \\ ${ }^{5}$ Department of Oncology, Combined Military Hospital, Rawalpindi, Pakistan
}

\begin{abstract}
Objective: To analyse the malignant chest wall tumors in terms of histological types and confer option for resection, stabilisation and reconstruction, along with postoperative morbidity and mortality.

Study Design: Observational study.

Place and Duration of Study: Department of Thoracic Surgery, CMH Rawalpindi, Lahore and Multan from January, 2010 to October, 2018.

Methodology: Patients who had histologically proven malignant tumors of chest wall and breast with bone involvement, and required resection, stabilisation, mesh reinforcement and muscle flap reconstruction, were included. Small soft tissue tumors without bony involvement which did not require reconstruction, primary tumors of spine, pancoast tumors and lung tumors involving chest wall were excluded from the study. Record of these patients including age, gender, histopathological type, reconstruction method used, postoperative complications, mortality and recurrence were noted. Data was analysed using descriptive statistics.

Results: The study included 86 patients with 61 (70.9\%) males and 25 (29.1\%) females; age ranging from 18 to 77 years with mean age of $47.84 \pm 12.9$ years. Palpable mass was the most common symptom occurring in 61 (70.9\%) patients. Twenty-one $(24.4 \%)$ had breast tumor with chest wall invasion. In the remaining cases, most common histological type was chondrosarcoma occurring in 13 (15.1\%) patients, followed by Ewing sarcoma in 12 (14\%) patients. The most common complication was post-thoracotomy neuralgia (PTN), occurring in $25(29.1 \%)$ patients.

Conclusion: Malignant tumors of the chest wall are rare entity which can be effectively treated with chest wall resection, mesh reinforcement for stabilisation and muscle flaps for reconstruction with acceptable postoperative complications, morbidity and mortality.
\end{abstract}

Key Words: Primary, Malignant, Chest wall, Tumors, Chest wall reconstruction, Stability of chest wall.

How to cite this article: Majeed FA, Ali A, Chatha SS, Ahmad G, Wyne A, Paracha N. Management of Malignant Chest Wall Tumors. J Coll Physicians Surg Pak 2021; 31(07):833-836.

\section{INTRODUCTION}

Primary tumors of the chest wall are considered as a heterogeneous group of tumors with an overall incidence of $1 \%$ to $2 \%$ in population and represent approximately $5 \%$ of all thoracic tumors. ${ }^{1-3}$ The group consists of tumors originating from bony as well as soft tissue components of the thoracic cage. Chest wall tumors have been classified by using various criteria such as the histological type, tissue of origin, benign or malignant etc.

Correspondence to: Dr. Sohail Saqib Chatha, Department of Thoracic Surgery, Combined Military Hospital, Rawalpindi, Pakistan

E-mail: drsohailchatha@hotmail.com

Received: June 11, 2020; Revised: December 04, 2020;

Accepted: December 22, 2020

DOI: https://doi.org/10.29271/jcpsp.2021.07.833
Among the benign category of chest wall, neoplasms are osteochondromas, chondromas, fibrous dysplasia, and desmoids tumors; ${ }^{4}$ whereas, malignant category includes soft-tissue sarcomas, osteosarcomas, chondrosarcomas, and the Ewing sarcoma family of tumors. ${ }^{5}$ Primary chest wall tumors are malignant in $50 \%$ to $80 \%$ of cases; and out of these, $55 \%$ take their origin either from the bone or cartilage; whereas, rest of the $45 \%$ originate from soft tissues. ${ }^{6}$

Malignant chest wall tumors either have presenting symptom of an enlarging palpable mass or can be asymptomatic and diagnosed as an incidental finding. Due to invasion of surrounding structures and involvement of neurological tissue, pain may also be a presenting symptom. Soft tissue masses are usually painless; whereas, those having bony origin are painful due to involvement of periosteum. Due to the extensive invasion of surrounding structures of the chest wall resection of the tumors usually result in extensive skeletal and soft tissue loss. These 
defects of the chest wall are covered either by the use of synthetic or biological meshes and / or soft tissue flaps having good vascularsupply.

The aim of this study was to analyse the characteristics of malignant chest wall tumors requiring reconstruction, histological types and the outcome of surgical method for resection, mesh stabilisation and muscle flap reconstruction, in term of acceptable postoperative complications, morbidity and mortality.

\section{METHODOLOGY}

This study was carried out in the Department of Thoracic Surgery, CMH Rawalpindi, CMH Lahore and CMH Multan from January 2010 to October 2018. A total of 86 patients were enrolled in the study after fulfilling the desired inclusion criteria via purposive sampling technique. Only those patients were included who had histologically proven malignant tumors of chest wall and breast with bone involvement and required resection, stabilisation, mesh reinforcement and muscle flap reconstruction. Small soft tissue tumors without bony involvement which did not require reconstruction, primary tumors of spine, pancoast tumors and lung tumors involving chest wall and tumors less than $5 \mathrm{~cm}$ without reconstruction, were excluded. Diagnosis was established with the help of core or incisional biopsy and all patients were discussed in multidisciplinary tumor boards.

Thorough history acquisition and local and systemic examination of all patients was carried out. In all patients enrolled in the study, lung function assessment, echocardiography, CT scan chest and abdomen with intravenous contrast and bone scan were carried out as mandatory workup. PET scan for metastatic workup and MRI were done in selective cases, depending on the MDT decision. The tumor resection was carried out with $4 \mathrm{~cm}$ margin, using unipolar electrocautry. One normal rib cephalic and caudal to the tumor was excised.

After confirming negative margins on frozen section, the primary reconstruction of the chest wall was carried out in all cases. It was supported by darn of prolene in order to give structural support and was reinforced with propene mesh $4 \mathrm{~cm}$ around, and covered with pediculate muscle flap. Chest tubes were placed in cases where pleural cavity was opened.

The patients were discharged on day 5 to 7 with post-op follow-up instructions, confirming expansion of the lungs via chest X-ray. Chest tubes were removed after postoperative follow-up and visits were planned as fortnightly for 2 months, then 3-monthly for a year and 6-monthly for next year. Patients were observed for postoperative complications such as surgical site infection, neuralgic pain, pneumothorax, pneumonia, recurrence and lung herniationetc.

The data was analysed in SPSS version 20.0, using descriptive statistics (frequencies, percentages, mean, median and mode).

\section{RESULTS}

There were 61 males (70.9\%) and 25 females (29.1\%) enrolled in the study with age ranging from 18 to 77 years with mean age of
$47.84 \pm 12.9$ years. Palpable mass was the most common symptom occurring in 61 (70.9\%), followed by chest pain in 20 $(23.3 \%)$ patients; whereas, fungating mass was the presenting symptom in only $5(5.8 \%)$ patients. Out of 86 patients, $21(24.4 \%)$ had breast tumor with chest wall invasion. Amongst the remaining tumors, most common histological type was chondrosarcoma occurring in 13 (15.1\%) patients, followed by Ewing sarcoma (post- chemotherapy) in 12 (14\%). There were seven cases of osteosarcoma, five cases of plasma cell tumor, four cases of dermatofibrosarcoma; three cases each of rhabdomyosarcoma, malignant aneurysmal cyst adenocarcinoma and gaint cell tumor; two cases each of dermatofibrosarcoma protuberns and malignant nerve sheath tumors; and one case each of papillary carcinoma, syringoma, neuroendocrine tumors, gastrointestinal stromal cell tumor (GIST), squamous cell carcinoma, malignant hemangiopericytoma and malignant fibrohistocytoma; and desmoid tumor each. Resection of the tumor was done with $4 \mathrm{~cm}$ of margin followed by reconstruction and augmented by various pediculate muscle flaps as shown in Table I. Latissimus dorsi (LD) muscle flap was the work horse flap in most of the reconstructions, i.e. 57 (66.3\%) patients.

The most common complication was post-thoracotomy neuralgia (PTN), occurring in $25(29.1 \%)$ patients, followed by seroma formation in $16(18.6 \%)$ of patients, pneumonia in 9 $(10.5 \%)$ patients, surgical site infection (SSI) in $5(5.8 \%)$ and haemothorax in one (1.2\%) case. All of the complications were managed; and there was no postoperative mortality. Blood transfusion was required in $38(44.2 \%)$ cases. There was no peri- or post-operative mortality; however, two patients needed ventilator support in postoperative period. Over a follow-up period of two years, there were $3(3.5 \%)$ recurrences with two cases of breast carcinoma and one of chondrosarcoma.

Table I: Types of muscle flaps used.

\begin{tabular}{|l|c|c|}
\hline Muscle flap used & No. of patients & Percentage \% \\
\hline Latissimus dorsi muscle flap & 57 & 66.3 \\
\hline Latissimus dorsi fasciocutaneous flap & 9 & 10.5 \\
\hline Serratus anterior muscle flap & 9 & 10.5 \\
\hline Pectoralis major muscle flap & 9 & 10.5 \\
\hline Omental flap & 2 & 2.3 \\
\hline
\end{tabular}

\section{DISCUSSION}

Primary tumors of the chest wall are an uncommon entity and can be classified further as benign as well as malignant. According to literature, $30 \%$ of the tumors are primary chest wall tumors, $20 \%$ originate from the breast, $40 \%$ from lungs, and $5 \%$ are other thoracic malignancies. ${ }^{5}$ Literature review shows that $60 \%$ of primary chest wall tumors are malignant. ${ }^{7}$ This study focused on malignant tumors of chest wall including the breast tumors invading the chest wall. Malignant chest wall tumors usually present in third or fourth decade of life. In a study conducted by Nabi et al., mean age was $38 \pm 16$ years with a range of 10 to 56 years; whereas, it was slightly higher in this study with a mean of $47.84 \pm 12.9$ years. ${ }^{8}$ The Memorial Sloan Kettering Cancer Center reported soft tissues as the tissue of origin of majority of primary chest wall tumors. ${ }^{9}$ 
In another study, carried out by Basso et al, osteosarcoma was the commonest histological type; whereas, in this study chondrosarcoma was most common type followed by Ewing sarcoma and then osteosarcoma. ${ }^{10}$ Patients usually present with symptoms of palpable mass, pain or both at tumor site. In a local study, $75 \%$ of patients presented with painless mass; whereas, in this study as well, mass was the main complaint occuring in $71 \%$ of patients. ${ }^{11}$ Treatment for small-sized tumors is excisional biopsy; whereas, in larger tumors a wider margin of about $4 \mathrm{~cm}$ is essential for successful management. In this study, a minimum margin of $4 \mathrm{~cm}$ was used. In another study by Bagheri et al. , $4 \mathrm{~cm}$ margin was used. ${ }^{12}$ In few of the studies done exclusively on chondrosarcoma, however, even a margin of 3 cm has been reported. ${ }^{13}$

After resection of the tumor with a wide margin primary closure is ideal, if possible. ${ }^{14}$ However, it was not possible in this study. In cases where primary closure is not possible, reconstruction of the chest wall is performed. Main aims of reconstruction are to maintain stability of the chest, to maintain adequate respiratory dynamics and preventing harmful paradox movements, and to achieve an acceptable cosmetic result. ${ }^{15}$ In order to achieve these results, prosthetic material is used in restoring the chest wall rigidity to avoid a paradoxical motion and covered with healthy soft tissue in order to protect the great vessels, viscera and prevent infection. ${ }^{16}$ In 2011, a study carried out by Guo et al. showed that single or combined flaps can be helpful while repairing the soft tissue defect. ${ }^{17}$ Most commonly used flap in achieving an adequate soft tissue coverage is by transpositioning the ipsilateral pedicled myocutaneous latissimus dorsi flap. In this study, as well, most commonly used flap was LD muscle flap and followed by LD fasciocutaneous flap. In cases when there are large full-thickness posteriorly located defects, use of free contralateral myocutaneous Latissimus dorsi flap is an acceptable option, which can help in achieving effective soft tissue coverage. ${ }^{18}$ In study conducted by Novoa et al. for anterolaterally located defects of chest wall, the use of Latissimus dorsi flap, which was transposed on thoracodorsal vessels was the preferred choice. ${ }^{19}$ Various other soft tissue coverage options in this study were use of pectoralis major, serratus anterior and greater omentum; and similar soft tissue coverage has been used in various other studies as well. ${ }^{20}$

In the study conducted by Mansour, the overall complication rate was $24 \%$ with pneumonia being the most common complication; $^{21}$ whereas, in this study post thoracotomy neuralgia, $29.1 \%$, was the most common complication. In the study conducted by King et al., recurrence rate of the tumor was $52 \% ;^{22}$ whereas, in this study recurrence occurred in $3(3.5 \%)$ patients over a 2-year follow- up. Probably, the reason for low recurrence in this study was use of a standardised wider margin of $4 \mathrm{~cm}$ for all tumors and selective loco-regional disease as per MDT. Hameed et al. in his study reported a recurrence rate of $15 \%$ over a follow-up period of 6 months, ${ }^{23}$ which was again higher as compared to this study. Abdel Rahman et al. reported a recurrence of $35.7 \% .{ }^{24}$ There was no operative and postopera- tive mortality in this study; and similarly no operative mortality was reported by King et al. in his study. Abdel Rahman et al. reported $1.02 \%$ operative related mortality; whereas, in few other studies a mortality of 3.8 to $4.5 \%$ has been reported. ${ }^{24,25}$ This can further be reduced by careful selection, preoperative evaluation and use of multidisciplinary approach in the management of such patients.

\section{CONCLUSION}

In malignant chest wall tumors, attaining a wider margin of resection is considered to be an important factor which minimises the local recurrence of tumor and also has a good effect on long-term survival of the patient. Wider excision of portion of chest wall along with ribs and later on reconstruction done with the help of propene/mesh and further augmented with local muscular flaps can be considered as a very safe and acceptable surgical option with minimal and overall acceptable rates of morbidity and mortality.

\section{PATIENT'S CONSENT:}

Informed consent was obtained from the patient regarding publication of data.

\section{ETHICALAPPROVAL:}

Ethical approval was obtained from the Ethical Committee of $\mathrm{CMH}$, Multan before starting the study.

\section{CONFLICT OF INTEREST:}

The authors declared no conflict of interest.

\section{AUTHORS' CONTRIBUTION:}

FAM: Conceived concept, outline and overall supervision. AA: Data collection, data entry, processing and formatting. SS: Data analysis, result writing, relevant literature search and preliminary write up.

GA: Critical revision, formatting and final writeup.

AW: Data processing, result correction and statistical guidance. NP: Final formatting of the manuscript and proof reading.

\section{REFERENCES}

1. Weisenburger TH. Overview of malignancies of the chest wall and pleura. In: Roth JA, Ruckdeschel JC, Weisenburger TH, editors. Thoracic oncology, 2nd ed. Philadelphia, PA: W.B. Saunders 1995. pp. 517-18.

2. Incarbone M. Pastorino U. Surgical treatment of chest wall tumors. World J Surg 2001; 25(2):218-30. doi: 10.1007/ s002680020022.

3. Hsu PK, Hsu HS, Lee HC, Hsieh CC, Wu YC, Wang LS, et al. Management of primary chest wall tumors: 14 years' clinical experience. J Chin Med Assoc 2006; 69(8): 377-82. doi: 10.1016/s1726-4901(09)70276-x.

4. Lukanich JM. Sugarbaker DJ. Chest wall and pleura.in: Townsend C.M. Beauchamp R.D. Evers B.M. Mattox K.L. Sabiston Textbook of Surgery: The Biological Basis of Modern Surgical Practice. 17th ed. Elsevier Saunders, Philadelphia, PA2004: 1715-17

5. Weyant MJ, Bains MS, Venkatraman E, Downey RJ, Park 
BJ, Flores RM, et al. Results of chest wall resection and reconstruction with and without rigid prosthesis. Ann Thorac Surg 2006; 81(1):279-85. doi: 10.1016/j. athoracsur.2005.07.001.

6. Burt M. Primary malignant tumors of the chest wall. The Memorial Sloan-Kettering Cancer Center experience. Chest Surgery Clinics of North America 1994; 4(1): 137-54.

7. Pass HI. Primary and metastatic chest wall tumors. In: Roth JA,Ruckdeschel JC, Weisenburger TH, editors. Thoracic oncology, $2^{\text {nd }}$ ed. Philadelphia, PA: W.B. Saunders, 1995. pp. 519-37.

8. Nabi MS, Bilal A, Khan FA, Ijaz A, Rana AO, Randhawa AF, et al. Surgical treatment of chest wall tumors (resection and reconstruction) A six years' experience. Ann King Edw Med Univ 2004; 10(1): 4-8. doi.org/10.21649/ akemu.v10i1.1131

9. Burt M. Primary malignant tumors of the chest wall: The memorial sloan-kettering cancer center experience. Chest Surg Clin N Am 1994; 4(1):363-9.

10. Preti, Vinicius, Gerardgo CG. Valladaress, Tariane F. Foiato, Jessica Takaki. Management of chest wall tumors: 15 years clinical experience, a retrospective study of 52 patients. Med Res Arch 2017; 5(6).

11. Salim M, Bilal A, Nabi MS. Primary chest wall neoplasms an experience of 39 patients. Ann King Edw Med Univ 2004; 10(1): 49-51. doi.org/10.21649/akemu.v10i1.1151.

12. Bagheri R Haghi SZ, Kalantari MR. Primary malignant chest wall tumors: analysis of 40 patients. J Cardiothorac Surg 2014; 19(9):106.

13. Briccoli A, De Paolis M, Campanacci L, Mercuri M, Bertoni F, Lari S, et al. Chondrosarcoma of the chest wall: A clinical analysis. Surg Today 2002; 32(4):291-6. doi: 10.1007/s005950200040.

14. McCormack PM. Use of prosthetic materials in chest-wall reconstruction. Assets and liabilities. Surg Clin North Am 1989; 69(5):965-76. doi: 10.1016/s0039-6109(16)449 32-7.

15. Mansour KA, Thourani VH, Losken A, Reeves JG, Miller JI Jr, Carlson GW, et al. Chest wall resection and reconstruction: A 25-year experience. Ann Thorac Surg 2002; 73(6):1720-5. doi: 10.1016/s0003-4975(02)03 527-0.
16. Weyant M, Bains M, Venkatraman E, Downey R, Park B, Flores $\mathrm{R}$, et al. Results of chest wall resection and reconstruction with and without rigid prosthesis. Ann Thorac Surg 2006; 81(1):279-85. doi: 10.1016/j. athoracsur.2005.07.001.

17. Guo L, Xing X, Li J, Xue C, Bi H, Li Z: Reconstruction of full-thickness chest wall defects. Zhongguo Xiu Fu Chong Jian Wai Ke Za Zhi 2011; 25(12):1465-68.

18. Bosc R, Lepage C, Hamou C, Matar N, Benjoar MD, Hivelin $M$, et al. Management of chest wall reconstruction after resection for cancer: A retrospective study of 22 consecutive patients. Ann Plast Surg 2011; 67(3):263-8. doi: 10.1097/SAP.0b013e3181f9b292.

19. Novoa N, Benito P, Jimenez MF, de Juan A, Luis Aranda J, Varela G. Reconstruction of 'chest wall defects after resection of large neoplasms: Ten-year experience. Interact CardioVasc Thorac Surg 2005; 4(3):250-5. doi: 10.1510/icvts.2004.103432.

20. Hultman CS, Culbertson JH, Jones GE, Losken A Kumar AV. Thoracic reconstruction with the omentum: Indications complications, and results. Ann Plas Surg 2001; 46 (3):242-49. doi: 10.1097/00000637-200103000-00007.

21. Mansour KA, Thourani VH, Losken A, Reeves JG, Reeves J, Miller Jr J, et al. Chest wall resections and reconstruction: A 25-year experience. Ann Thorac Surg 2002; 73(6): 1720-6. doi: 10.1016/s0003-4975(02)03527-0.

22. King RM, Pairolero PC, Trastek VF, Piehler JM, Payne WS, Bernatz PE. Primary chest wall tumors: Factors affecting suwival. Annals Thoracic Surg 1986; 41(6): 597-601. doi: 10.1016/s0003-4975(10)63067-6.

23. Hameed A, Akhtar S, Naqvi A, Pervaiz Z. Reconstruction of complex chest wall defects by using polypropylene mesh and a pedicled latissimus dorsi flap: A 6-year experience. J Plast Reconstr Aesthet Surg 2008; 61(6):628-35. doi: 10.1016/j.bjps.2007.04.011.

24. Rahman, Abdel Rahman Mohamed Abdel, Rahouma M, Gaafar R, Bahaa S, Loay I, et al. Contributing factors to the outcome of primary malignant chest wall tumors. J Thoracic Disease 2017; 12(9):5184-93. doi: 10.21037/jtd.2017. 11.61.

25. Allen MS, Mathisen DJ, Grillo HC, Wain JC, Moncure AC, Hilgenberg AD. Bronchogenic carcinoma with chest wall invasion. Ann Thorac Surg 1991; 51:948-51. 